\title{
Uterine rupture: a preventable obstetric catastrophe
}

\author{
Bina M. Raval, Apoorva G. Patil*, Parav D. Shah
}

Department of Obstetrics and Gynecology, Smt. NHL MMC Ahmadabad, Gujarat, India

Received: 05 October 2019

Revised: 15 November 2019

Accepted: 19 November 2019

\section{*Correspondence:}

Dr. Apoorva G. Patil,

E-mail: apoorvapatil12@gmail.com

Copyright: (C) the author(s), publisher and licensee Medip Academy. This is an open-access article distributed under the terms of the Creative Commons Attribution Non-Commercial License, which permits unrestricted non-commercial use, distribution, and reproduction in any medium, provided the original work is properly cited.

\begin{abstract}
Background: Maternal health has long been acknowledged to be the cornerstone in public health. The objective of this study was to determine the incidence, etiology, risk factors, complications, treatment strategies, maternal and fetal outcome associated with uterine rupture and to determine how to decrease the maternal morbidity and mortality pertaining to it, as it is indeed a preventable obstetric catastrophe!

Methods: This is a retrospective study which was carried out in our institute. Analysis of 45 cases of uterine rupture including scar dehiscence, registered/emergency, rupture occurring in the antepartum or intrapartum period, irrespective of previous vaginal or cesarean delivery was done between July 2017 to June 2019 out of 16,330 deliveries. None of the cases were excluded. Statistical analysis was done comparing the mortality in general population and study population and it was determined that it contributes to the maternal mortality significantly hence making it essential to promptly diagnose and treat the cases.

Results: The incidence of rupture of uterus is average $0.27 \%$ ( 1 in 362). Out of 45 cases 9 (20\%) were registered, and $36(80 \%)$ were referred patients. The $20-30$ years age group is the most vulnerable. Scarred uterus undergoing rupture were $34(75.55 \%)$ as compared to rupture in intact uterus which were $11(24.44 \%)$. The commonest modality of treatment used is suturing of tear which was done in $34(75.55 \%)$ followed by total hysterectomy. There were 2 maternal deaths giving maternal mortality rate of $4.44 \%$ and perinatal mortality occurred in $18(40 \%)$ cases.

Conclusions: Uterine rupture is a dire emergency with a high incidence of maternal and fetal morbidity and mortality. Skilled attendance with accessible obstetric care, focused antenatal care, strict intrapartum monitoring and good surgical approach are key elements for the prevention and management of uterine rupture.
\end{abstract}

Keywords: Cesarean section, Hysterectomy, Mortality, Uterine rupture

\section{INTRODUCTION}

Maternal health has long been acknowledged to be the cornerstone in public health. Uterine rupture is a catastrophic complication in women that is mostly seen in cases of prior cesarean section. There has been an observed shift in etiology from obstructed labor and multiparty towards rupture of cesarean scar. Delee had said 'once a cesarean section always a cesarean section' but according to Munro Kerr the dictum has changed to 'once cesarean section always a hospital delivery'. ${ }^{1}$ Trial of scar has helped to decrease the number of repeat cesarean section in the cases where there are no recurrent indications.

The hospital-based incidence varies from 1 in 500 deliveries in developing countries to 1 in 3000 in hospitals with well-developed health services. In India the incidence varies between 0.3 and 7/ 1000 deliveries.

Uterine rupture is a serious event during childbirth in which myometrial wall is breached. It can be classified as 
complete in which all layers of uterine wall are separated and incomplete in which uterine muscle is separated but the visceral peritoneum is intact which is known as scar dehiscence.

Rupture of unscarred uterus may be either spontaneous or traumatic. Traumatic factors include abdominal trauma, injudicious use of oxytocics, instrumental delivery, assisted breech delivery, shoulder dystocia, manual removal of placenta and internal podalic version. Spontaneous rupture is associated with previous uterine scar, cephalopelvic disproportion, malposition, malpresentation, delivery of macrosomic baby, grand multipara and congenitally abnormal uterus.

The most critical aspects of treatment of uterine rupture are establishing a timely diagnosis and minimizing the time from onset of signs and symptoms until the start of definitive surgical treatment. Identifying the high-risk pregnancies for rupture uterus and their timely referral is an important step in secondary prevention. Hysterectomy once an accepted mode of treatment for ruptured uterus does not find favour with modern obstetrics and more conservative methods have been suggested like suturing of the rent with or without sterilization and elective cesarean is the next confinement.

Indeed, it's not an exaggeration to say that the incident of uterine rupture is an index of obstetric civilization of a country, these two factors being inversely proportional to each other.

\section{METHODS}

This is a retrospective study of rupture of gravid uterus, carried out in our institute from July 2017 to June 2019.

\section{Source of data}

All the cases of ruptured uterus in this institute during the given time period of July 2017 to June 2019were studied. A total of 45 cases of uterine rupture were studied out of a total number of 16,330 deliveries.

\section{Inclusion criteria}

- All the cases having complete and incomplete uterine ruptures

- Cases were included irrespective of previous vaginal deliveries or previous cesarean sections

- Cases of uterine rupture occurring during antepartum and intrapartum period

- $\quad$ Referred and registered both types of cases included

\section{Exclusion criteria}

- None

During the given study period there were no cases observed which had rupture uterus due to history of previous gynecological surgeries like myomectomy, repair of anomalous uterus etc.

Patient's sociodemographic variables like age, socioeconomic status, parity, antenatal care taken, clinical presentation and previous detailed surgical history of number of cesarean sections, dilatation and evacuations etc was recorded. Rupture was labelled as complete when the entire thickness of uterine wall along with visceral peritoneum had given way, irrespective of extrusion of fetal parts. All other types were grouped under incomplete rupture. The site and type of rupture, nature of surgery performed, number of units of blood transfused, maternal and fetal outcome were documented. Incidence of rupture was calculated from total number of deliveries that had occurred in the hospital during the study period. Mothers were followed throughout the postoperative period for maternal complications like evidence of sepsis, abdominal distension, fever, wound healing, DIC were noted.

Different operations done in this study are:

- Suturing of rupture with or without sterilization depending on obstetric history

- Subtotal hysterectomy

- Total hysterectomy.

Associated bladder injuries were repaired and in certain cases internal iliac artery ligation was required.

\section{Statistical analysis}

The maternal mortality of the general population and the study population has been compared and chi square test has been applied. It has been determined that uterine rupture does increase maternal mortality and hence early diagnosis and prompt intervention is required. Supplementary file is attached.

\section{RESULTS}

In the present study (2017-19) there were 45 cases of uterine rupture out of 16,330 deliveries giving an incidence of $1: 362$.

Table 1 shows, $36(80 \%)$ cases were emergency cases and $9(20 \%)$ were registered. Most common age group that proved to be vulnerable was between 20-30 $(86.66 \%)$. It was seen that when the inter-pregnancy interval was less than 2 years, the incidence of rupture was highest i.e. 27 out of 45 cases $(60 \%)$. Uterine rupture was seen maximum in para 1-3 $(88.88 \%)$.

As described, in (Table 2), women with previous cesarean sections were 34 cases $(75.55 \%)$ out of which 1 case was of a classical cesarean section and 17 cases were of previous 1 cesarean section. Obstruction was seen in 5 cases $(11.11 \%)$ and malpresentation in 3 cases $(6.66 \%)$. 
Induction with uterotonics lead to rupture in 2 cases $(4.44 \%)$ and instrumental delivery in 1 case $(2.22 \%)$.

Table 1: Incidence of rupture uterus with regard to socio-demographic variables.

\begin{tabular}{|lll|}
\hline $\begin{array}{l}\text { Socio-demographic } \\
\text { variables }\end{array}$ & $\begin{array}{l}\text { Number of } \\
\text { cases }\end{array}$ & $\%$ \\
\hline Nature of admission & & \\
\hline Referred & 36 & $80 \%$ \\
\hline Registered & 9 & $20 \%$ \\
\hline Age (years) & & \\
\hline $20-30$ & 39 & $86.66 \%$ \\
\hline$>30$ & 6 & $13.33 \%$ \\
\hline Inter pregnancy interval (years) & \\
\hline$<2$ & 27 & $60 \%$ \\
\hline $2-4$ & 15 & $33.33 \%$ \\
\hline$>2$ & 3 & $6.66 \%$ \\
\hline Parity & & \\
\hline Primipara & 2 & $4.44 \%$ \\
\hline $1-3$ & 40 & $88.88 \%$ \\
\hline$>3$ & 3 & $6.66 \%$ \\
\hline
\end{tabular}

Table 2: Aetiology.

\begin{tabular}{|lll|}
\hline Predisposing factor & $\begin{array}{l}\text { Number of } \\
\text { cases }\end{array}$ & $\%$ \\
\hline Previous scar & 34 & $75.55 \%$ \\
\hline Classical & 1 & \\
\hline Previous 1 scar & 17 & \\
\hline Previous 2 scar & 12 & \\
\hline Previous 3 scar & 3 & $11.11 \%$ \\
\hline Previous 4 scar & 1 & $6.66 \%$ \\
\hline Obstruction & 5 & $4.44 \%$ \\
\hline Malpresentation & 3 & $2.22 \%$ \\
\hline Induction with uterotonics & 2 & \\
\hline Instrumental delivery & 1 & \\
\hline
\end{tabular}

Table 3: Characteristic of rupture.

\begin{tabular}{|lll|}
\hline Characteristic of rupture & $\begin{array}{l}\text { Number of } \\
\text { cases }\end{array}$ & $\%$ \\
\hline Nature of rupture & & \\
\hline Complete & 12 & $26.66 \%$ \\
\hline Incomplete & 33 & $73.33 \%$ \\
\hline Site of rupture & & \\
\hline Upper segment & 2 & $4.44 \%$ \\
\hline Lower segment & 42 & $93.33 \%$ \\
\hline Posterior surface of uterus & 1 & $2.22 \%$ \\
\hline
\end{tabular}

Table 3 shows the nature of rupture in which incomplete rupture was seen in 33 cases $(73.33 \%)$ and complete rupture in 12 cases $(26.66 \%)$. Most common was rupture in lower segment of uterus seen in 42 cases $(93.33 \%)$ and in 2 cases (4.44\%) upper segment rupture was seen. It was possible to repair the rent in 34 cases $(75.55 \%)$ whereas hysterectomy needed to be performed in 11 cases $(24.44 \%)$. The associated injuries were broad ligament hematoma seen in 7 cases $(15.55 \%)$, bladder injury in 4 cases $(8.88 \%)$ and colporrhexis in 2 cases $(4.44 \%)$. Blood transfusions were required in 26 cases $(57.77 \%)$.

Table 4: Associated injuries and modality of treatment.

\begin{tabular}{|lll|}
\hline \multicolumn{2}{|c|}{$\begin{array}{c}\text { Number } \\
\text { of cases }\end{array}$} \\
\hline Associated injury & \multicolumn{2}{l|}{} \\
\hline Broad ligament hematoma & 7 & $15.55 \%$ \\
\hline Colporrhexis & 2 & $4.44 \%$ \\
\hline Bladder injury & 4 & $8.88 \%$ \\
\hline Treatment modality & & \\
\hline Suturing of rupture & 34 & $75.55 \%$ \\
\hline Subtotal hysterectomy & 5 & $11.11 \%$ \\
\hline Total hysterectomy & 6 & $13.33 \%$ \\
\hline Repair of bladder & 4 & $8.88 \%$ \\
\hline Internal iliac artery ligation & 5 & $11.11 \%$ \\
\hline Blood transfusions & 26 & $57.77 \%$ \\
\hline
\end{tabular}

Table 5: Fetal and maternal outcome.

\begin{tabular}{|lll|}
\hline Outcome & $\begin{array}{l}\text { Number } \\
\text { of cases }\end{array}$ & $\%$ \\
\hline Fetal outcome & \multicolumn{2}{l|}{} \\
\hline Live & 27 & $60 \%$ \\
\hline Still born or intra uterine death & 18 & $40 \%$ \\
\hline Maternal outcome & & \\
\hline Live & 43 & $95.55 \%$ \\
\hline Mortality & 2 & $4.44 \%$ \\
\hline
\end{tabular}

Table 6: Mentions the various post-operative complications.

\begin{tabular}{|lll|}
\hline Post operative complications & $\begin{array}{l}\text { Number } \\
\text { of cases }\end{array}$ & $\%$ \\
\hline Fever & 13 & $28.88 \%$ \\
\hline $\begin{array}{l}\text { Disseminated intravascular } \\
\text { coagulation }\end{array}$ & 3 & $6.66 \%$ \\
\hline Acute renal failure & 2 & $4.44 \%$ \\
\hline Septicaemia & 4 & $8.88 \%$ \\
\hline Haemorrhagic shock & 7 & $15.55 \%$ \\
\hline Paralytic ileus & 2 & $4.44 \%$ \\
\hline Wound infection & 5 & $11.11 \%$ \\
\hline
\end{tabular}

Out of 45 cases still births or intrauterine deaths occurred in 18 cases $(40 \%)$ and 27 fetuses were live $(60 \%)$. In 43 cases $(95.55 \%)$ the maternal outcome was favourable whereas in 2 cases $(4.44 \%)$ maternal mortality occurred.

The most common complication occurring in the postoperative patients was fever $(28.88 \%)$ followed by hemorrhagic shock (15.55\%). Septicemia occurred in 4 cases $(8.88 \%)$, wound infection in $(11.11 \%)$, acute renal failure in 2 cases $(4.44 \%)$ and DIC in 3 cases $(6.66 \%)$. 


\section{DISCUSSION}

The incidence of rupture of uterus in the study is average $0.27 \%$. In the study of Pereira et al, the incidence during 1998-1999 was $0.34 \%$ and in study of Latika et al, was $0.28 \%$ and in study done by Gupta A incidence was $0.11 \%$. $^{2-4}$ This decreasing incidence may be due to better obstetric care, modern investigation facilities like USG which is available at tertiary care centre with expert team of gynecologist, anesthetist and radiologist.

But, in India majority of people belong to lower socioeconomic class suffering from poverty, illiteracy, lack of health care facilities and lack of transport and communication. Because of lack of adequate antenatal care most of the patients were unregistered. This is comparable with the study of Shumaila Zia et al, in which $73 \%$ were referred cases. ${ }^{5}$

The highest incidence of rupture is in the 20-30 years age group i.e. $86.66 \%$ because this is the maximum child bearing age. It's comparable with Latika et al, in which $73 \%$ occurred in 20-30 years female. ${ }^{3}$ Stamilio et al, showed that short inter pregnancy interval leads to increased risk which is corresponding to our study in which maximum cases belong to $<2$ years interval $(60 \%){ }^{6} 88.88 \%$ cases belonged to para $1-3$ which is comparable to the study of Sahu et al, in which it is $75.26 \% .^{3}$ This is because of increase in the acceptance of small family norms. In the present study $60 \%$ patients had inter pregnancy interval less than 2 years. It's speculated that a prolonged inter pregnancy interval may allow time for the previous cesarean scar to reach its maximal tensile strength to undergo mechanical stress and strain of next intra uterine pregnancy. Kok N, and Wiersma IC showed that lower uterine segment thickness cut off between 0.6-2 $\mathrm{mm}$ provided a strong positive predictive value for the occurrence of uterine rupture. $^{7}$

In the present study the most common etiological factor proved to be previous cesarean sections i.e $75.55 \%$ which is comparable with Shumaila Zia et al, wherein $88 \%$ cases were due to previous cesarean sections, with Kiesser and Baskett et al study in 2002 in which 92\% cases were due to previous cesarean sections and also in the study by Sheikh BN. ${ }^{5,8,9}$ Obstructed labor due to cephalopelvic disproportion was a major etiological factor in the studies of Khanam RA et al, 1994-1999 $(48 \%) .{ }^{10}$ Hence this shows the changing trend in the etiology of rupture uterus.

In the present study, $93.33 \%$ ruptures were in the lower uterine segment because of the rare usage of classical cesarean section or hysterotomy which resembles the results of Latika et al, which shows $89.7 \%$ of lower uterine ruptures. ${ }^{3}$

The scar rupture site was repaired in $75.55 \%$ of patients in an attempt to conserve the uterus which is comparable to study of Latika et al. ${ }^{3}$ In older studies like Khanam RA et al, almost $70 \%$ patients underwent hysterectomy. In our study a total of only $24.44 \%$ patients had hysterectomies performed indicating the changing trends towards conservative management. ${ }^{10}$ However it's not always easy to perform repair, as uterine walls are friable and approximation of edges maybe difficult which may result in post-operative sepsis. But ultimately choice of surgical treatment depends on type and extent of uterine rupture, degree of haemorrhage, general condition of the mother and mother's desire for future child bearing. Fetal condition depends on the degree to which the placental implantation remains intact, although this can change within minutes. ${ }^{11}$ Associated operative measures like ligation of anterior division of internal iliac artery, repair of broad ligament hematoma and bladder repair was done as and when required.

Only $28.88 \%$ patients developed post-operative fever and $11.11 \%$ had wound infection. Blood transfusions were required in $57.77 \%$. Maternal mortality was seen in 2 cases $(4.44 \%)$ and perinatal mortality in 18 cases (40\%). In a study done by Sahu et al, maternal mortality was $2.76 \%$ and in Shumaila et al, study the perinatal mortality was $33 \%$ which is comparable to our study. ${ }^{3,5}$ The main cause of maternal mortality was failure to diagnose the condition at the first referral center and arrival at the tertiary centre in an unstable condition. Perinatal mortality is due to hypoxia caused by immediate placental separation.

\section{CONCLUSION}

Rupture of uterus is a potentially life-threatening devastating yet a preventable complication. But, over the years with improved obstetric care there is a decrease in number of cases resulting from obstructed and unattended labors. At the same time, there is a significant raise in rupture of previous cesarean section scar.

Reducing the primary cesarean section rate and optimizing care for women with previous scar will go a long way in reducing the overall incidence. Hence think twice before first cesarean and don't hesitate in taking for cesarean in a previous cesarean at the earliest indication.

Women with previous scar and high risk for rupture opting for trial of labor should be carefully chosen and continuously monitored for fetal heart abnormalities and scar tenderness. More vigilant approach to prevent prolonged and obstructed labor, training the health care workers in the use of partograph, along with high index of suspicion and prompt referral to a higher centre with availability of an experienced surgeon, good anesthetic, blood bank, ICU and NICU will help in decreasing maternal and perinatal morbidity and mortality.

\section{Funding: No funding sources \\ Conflict of interest: None declared \\ Ethical approval: Not required}




\section{REFERENCES}

1. Baskett TF, Calder AA. Caesarean section. Baskett TF, Calder AA, Arulkumaran S, editors. Twelft: Elsevier. $2014 \mathrm{~J}: 132-44$.

2. Pereira LS, Lira PJ, Ahued AR, Quesnel Garcia BC. Maternal mortality in adolescent pregnancy. Ginecol Obstet Mex. 1999;70:270-4.

3. Sahu L. 10-year analysis of uterine rupture at a teaching institution. J Obstet Gynecol India. 2006;56(6):502-6.

4. Gupta A, Nanda S. Uterine rupture in pregnancy: a five-year study. Arch Gynecol Obstet. 2011;28(3):437-41.

5. Zia S, Refique M, Rizwan A, Amin AB, Khan AB, Khan $T$. Uterine rupture: changing trends in obstetrics and lessons for obstetricians. J South Asian Feder Obstet Gynecol. 2012;4(3):155-8.

6. Stamilio DM, DeFranco E, Paré E, Odibo AO, Peipert JF, Allsworth JE, et al. Short interpregnancy interval: risk of uterine rupture and complications of vaginal birth after cesarean delivery. Obstet Gynecol. 2007;110(5):1075-82.

7. Kok N, Wiersma IC, Opmeer BC, De Graaf IM, Mol BW, Pajkrt E. Sonographic measurement of lower uterine segment thickness to predict uterine rupture during a trial of labor in women with previous Cesarean section: a meta-analysis. Ultrasound Obstet Gynecol. 2013;42(2):132-9.

8. Kieser KE, Baskett TF. A 10-year population-based study of uterine rupture Obstet Gynecol. 2002;100(4):749-53.

9. Sheikh BN, Sheikh S, Sheikh F, Raisham. Medical channel: uterine rupture an ongoing tragedy of motherhood. Med Channel. 2013;19(4):24-8.

10. Khanam RA, Khatun M. Ruptured uterus: an ongoing tragedy of motherhood, Bangladesh. Med Res Counc Bull. 2001;27(2):43-7.

11. Cunningham, Leveno, Bloom, Dash, Hoffman, Casey, Spong. Prior caesarean delivery: Williams Obstetrics, $24^{\text {th }}$ Ed; 2015:617.

Cite this article as: Raval BM, Patil AG, Shah PD. Uterine rupture: a preventable obstetric catastrophe. Int J Reprod Contracept Obstet Gynecol 2020;9:1515. 